\title{
Article
}

\section{How Danish dentists and dental hygienists handle their role in child abuse and neglect matters}

Uldum, Birgitte, Christensen, Hanne Nødgaard, Welbury, Richard and Haubek, Dorte

Available at http://clok.uclan.ac.uk/17314/

Uldum, Birgitte, Christensen, Hanne Nødgaard, Welbury, Richard ORCID: 0000-0002-9322-2440 and Haubek, Dorte (2017) How Danish dentists and dental hygienists handle their role in child abuse and neglect matters. Acta Odontologica Scandinavica . pp. 1-6. ISSN 0001-6357

It is advisable to refer to the publisher's version if you intend to cite from the work. http://dx.doi.org/10.1080/00016357.2017.1307448

For more information about UCLan's research in this area go to http://www.uclan.ac.uk/researchgroups/ and search for <name of research Group>.

For information about Research generally at UCLan please go to http://www.uclan.ac.uk/research/

All outputs in CLoK are protected by Intellectual Property Rights law, including Copyright law. Copyright, IPR and Moral Rights for the works on this site are retained by the individual authors and/or other copyright owners. Terms and conditions for use of this material are defined in the policies page.

\section{CLoK}

Central Lancashire online Knowledge www.clok.uclan.ac.uk

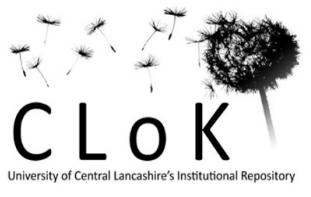


How Danish dentists and dental hygienists handle their role in child abuse and neglect matters

Birgitte Uldum ${ }^{1}$, Hanne Nødgaard Christensen ${ }^{2}$, Richard Welbury ${ }^{3}$ and Dorte Haubek ${ }^{4 *}$ ${ }^{1}$ Municipal Dental Service for Children and Adolescents, Copenhagen, Denmark

${ }^{2}$ Child Protection Centre, Aarhus University Hospital, Department of Pediatric

${ }^{3}$ University of Central Lancashire Dental School, Preston, UK

${ }^{4}$ Section of Paediatric Dentistry Health, Aarhus University, Aarhus, Denmark

Running title: Danish dental team and child protection

Word count: 4440

Figures: 1

Tables: 3

Correspondence address:

Professor Dorte Haubek PhD, Dr. Odont.

Department of Dentistry, Section of Pediatric Dentistry,

Health, Aarhus University,

Vennelyst Boulevard 9, DK-8000 Aarhus C

Denmark

E-mail: dorte.haubek@dent.au.dk

Telephone: (0045) 87168092 


\section{Abstract}

Objective: To identify how the dental team perceives its role in safeguarding children, to identify barriers to referral to social services, to compare data with data previously reported from Denmark, and to assess if increased focus on safeguarding children has had an effect on how the dental team handles its responsibility to refer to social services.

Material and methods: The study is based on a Danish version of a questionnaire previously used in Scotland and Denmark. The questionnaire was sent to a random sample of the Danish dental team. Results: The number of returned questionnaires was $964(67.0 \%)$ with valid data. Of these, $40.8 \%$ had had a suspicion of child abuse or neglect and $50.0 \%$ had referred their concern to social services. Frequently reported barriers to referral were uncertainty about observations, signs, and symptoms of abuse and neglect, and uncertainty about referral procedures. A total of $84(8.9 \%)$ of the respondents had received both undergraduate and postgraduate training on the topic, and $64.4 \%$ of the respondents found that the dental staff could recognize signs and symptoms of abuse and neglect.

Conclusion: Findings suggest a continuous need for a focus on the awareness and training of the Danish dental staff on the important topic of child abuse and neglect.

Keywords: child maltreatment, Danish dentists, reporting 


\section{Introduction}

In recent years, attention on the role of the dental team in contributing to safeguarding children has been evident in many countries, e.g., in the UK, in Sweden, in the Netherlands, and in Denmark [15]. A study from Scotland, published in 2013 [6], reported that Scottish dentists appear to suspecting and referring more cases of child abuse and neglect than in 2005 [7], and in a recent

study from the Netherlands, where the Mandatory Reporting Code Act has come into force recently, it was reported that $24 \%$ of Dutch general dental practitioners have had a suspicion of a domestic violence case or a case of child abuse within the last twelve months [4].

To a great extent, the Danish dental team is in a unique position to identify vulnerable children and adolescents. Firstly, the majority of signs of physical abuse presents in the head and neck region [8-13]. Secondly, all Danish children and adolescents are offered tax-financed comprehensive dental care in public clinics and less commonly in private practices. The dental teams treating children and adolescents must react if someone does not respond to invitation and subsequently does not attend dental visits. Finally, members of the dental team are obliged by Danish legislation, the Social Assistance Act section 153, to refer their concern for a child or an adolescent in need of additional social support to social services.

A previous Danish study [5] has reported on how the Danish dental team perceives its role in child protection matters and identified barriers to referral to social services [5]. The most common barriers to referral were uncertainty about clinical observations and lack of knowledge regarding referral procedures. As a result of the previously reported Danish data, focus on child protection issues has been intensified in Denmark. Since 2009 postgraduate educational courses on the topic 
aimed at all dental professionals, though not mandatory, have increased significantly in numbers. In 2010, undergraduate courses were established at the universities, and the universities also started a fruitful collaboration with the ombudsman for children in Denmark. The study by Uldum et al. [5] may possibly have contributed to the revision of the Social Assistance Act in 2011 in order to include the dental team in the inter-collegial early actions to safeguarding children.

The aims of the present study were to re-evaluate how Danish dentists and dental hygienists fulfill their role in child protection matters, to identify barriers to referral to social services and then to compare this data with previously collected Danish data in order to assess if the increased focus on child protection issues over a five-year period in Denmark has had an effect on how the dental team handles its responsibility to refer to social services.

\section{Material and methods}

\section{Modification of questionnaire into Danish version}

The data collected in the present study is based on a questionnaire similar to the one used in the study conducted in 2008 [5]. A Danish version of the original questionnaire, designed by Cairns and co-workers in 2005, was used [7]. Briefly, the original Scottish questionnaire was translated into Danish, then adapted to Danish conditions and terminology, and piloted on a small group of dentists and dental hygienists. A few adaptations were made to improve the understanding, followed by a back-translation into English. On both occasions the questionnaire was translated and compared to the original by a bilingual (English and Danish) person with insight into dentistry. Throughout the questionnaire, the term 'child abuse and neglect' was used as a set term, and the respondents were not invited to elaborate on types of abuse. In the introduction to the questionnaire, the WHOdefinition of child abuse and neglect was quoted [14], and the questionnaire consisted of 27 questions. Briefly, the questions were on (1) demographics and employment; (2) dental education; 
(3) suspicion of child abuse and neglect, (4) referring to social services and barriers to referral; (5) knowledge of local child protection guidelines; (6) undergraduate and postgraduate training in child protection, present knowledge and perceived need for further education.

\section{Study population and sample size}

The questionnaire was sent by conventional post to a random $25 \%$ sample of all Danish dentists and dental hygienists. Both dentists and dental hygienists were included in the study as they have an individual obligation to refer any professional concern about vulnerable children and adolescents to social services. The sample of invited participants was drawn from lists obtained in July 2013 from the three organizations that are organizing dentists and dental hygienists in Denmark. As some dentists and dental hygienists, living at the Faroe Islands and in Greenland, are members of one of the Danish organizations, a few questionnaires were sent to dentists and dental hygienists employed on the Faroe Islands and in Greenland. Both nations are self-governing within the Kingdom of Denmark. All members of the sample received an envelope with the questionnaire, a cover letter and a pre-paid postage return envelope. It was sent out to the study population in August 2013, and reminders were sent after 4 and 8 weeks to increase the response rate.

\section{Statistical analysis}

The data were entered in the PC twice using EpiData version 3.1 to ensure the data quality and subsequently analyzed using SPSS v.21 (SPSS Inc., Chicago, Il, USA). Descriptive statistical methods were used and chi-squared $\left(\chi^{2}\right)$ tests were used to test associations. The level of significance was set at $5 \%(\alpha=0.05)$.

Based on the collected data, two variables were defined. The first aggregated (dichotomized) variable covered dental staff treating children, which could take place in a combination of various 
employment types. The 'value 0' was assigned to dental staff employed in private practice not treating children on a regular basis. The 'value 1' was assigned to combinations of the following three employment types; municipal dental service, private practice treating children and/or private practice treating children, but not on a regular basis (e.g., only in acute trauma cases after closing hour of dental clinics in the municipalities).

The concept of the second variable was to define individuals who are confident with the municipal dental service and have some or their whole employment in this system ('value 1'); whereas the remaining ('value 0') covered staff members employed in private practice without child patients, and with no employment in the municipal dental service in Denmark.

\section{Results}

Of the 1438 questionnaires that were sent, $964(67.0 \%)$ were returned with valid data. Of the remaining questionnaires; 452 were not returned; five pre-paid postage return envelope were returned but were empty when opened; ten were returned labeled 'address unknown'; and the last seven were returned unanswered.

\section{Demographics}

Table 1 shows gender, age, dental education, the type of employment, and parenthood of the present study population as well as the Danish study population reported on five years ago [5] . With respect to gender and age, the distributions were comparable in the two studies (Table 1). Overall, a high proportion of females (above 70\%) in both populations was found. Furthermore, it is evident that the proportion of young dental staff members is higher than older staff members $(60 \% \leq 50$ years old). In both samples, dentists accounted for three quarters of the respondents. With respect to gender, age and dental education, the sample reflects the composition of dental staff in Denmark. 
Slightly more than half of the respondents $(53.4 \%)$, treating patients and being employees in municipal dental service and/or in private practice, treated children on a regular basis. This holds true in the samples both from 2008 and 2013. More than $80 \%$ of the respondents were a parent themselves (Table 1).

Frequency of having a suspicion of child abuse and neglect, referring to social services, choice of communication partners, and the development over a five-year period in Denmark

Of the $40.8 \%$ respondents who had had suspicion of child abuse or neglect at some point during their career, $50.0 \%$ had referred their concern to social services, whereas this was only the case for $33.9 \%$ in the previously reported data [5]. During their career, $30.0 \%$ of the respondents reported having had a suspicion without referring to social services, and of these, $53.8 \%$ made a note of the concern in the child's clinical record. Over the five-year period, from 2008 to 2013, a slight increase of having a suspicion of child abuse or neglect was seen, i.e., $38.3 \%$ vs. $40.8 \%$, respectively, whereas referrals to social services had increased considerably during the same period.

In Table 2, the distribution of respondents, reporting suspicion or being certain of child abuse and neglect within the last six months according to the type of the employment, is shown. A slightly higher proportion of respondents in the present study reported suspicion of child abuse and neglect within the last six months than in the study carried out in 2008 , i.e., $17.9 \%$ vs. $13.6 \%$, respectively. Of the $17.9 \%$ respondents in the present study having had a suspicion, some $66.3 \%$ were employed in the municipal dental service, whereas $33.7 \%$ were employed in private practice either with or without child patients. Furthermore, results showed that $8.6 \%$ of the respondents in the present study in contrast to $6.8 \%$ in previously reported data [5] had been certain of child abuse and neglect within the last six months (Table 2). 
Table 3 presents the respondents' choice of resource person or agency to communicate with in a hypothetical child abuse or neglect case and in an actual case. The vast majority (more than $80 \%$ ) of the respondents would prefer to discuss or refer their concern to either social services and/or colleagues. Relatively few would choose to involve the police (Table 3).

\section{Frequency of types of barriers and the development over a five-year period}

The most frequently reported barriers to referral to social services were uncertainty about the observations, signs and symptoms of abuse and neglect (72.4\%), fear of additional violence towards the child when the caregiver learns about the referral (63.5\%), uncertainty about the referral procedures $(60.8 \%)$, and fear of the consequences to the child, if the authorities intervene (54.5\%) (Fig.1). Almost similar percentages were found in the data reported on previously [5].

\section{Training in the management of child abuse and neglect cases}

Concerning the frequency of the respondents having received training on child abuse and neglect, slightly more than half of the respondents had not received any training, neither undergraduate nor postgraduate training, i.e., 55.7\%. A slightly higher proportion of respondents, who had been trained, had received postgraduate training compared to undergraduate training, i.e., $20.6 \%$ vs. $14.9 \%$, respectively. Only a small proportion of the respondents $(8.9 \%)$ had received both undergraduate and postgraduate training on the topic.

Among dental staff treating children (first dichotomized variable), more had received undergraduate training compared to dental staff not treating children $(27.9 \%$ vs. $18.8 \%, \mathrm{p}<0.05)$. This observation was significantly increased when looking at postgraduate training $(50.7 \%$ vs. $5.9 \%, \mathrm{p}<0.05$ ). When looking at employment type (second dichotomized variable), $21.1 \%$ of the staff in private practice had received undergraduate training compared to $30.6 \%$ of the staff in 
municipal dental service $(\mathrm{p}<0.05)$. An increase was seen concerning postgraduate training where $77.2 \%$ of staff in municipal service had received postgraduate training compared to only $10.3 \%$ of the staff in private practice $(\mathrm{p}<0.05)$.

Slightly more than half of the respondents $(64.4 \%)$ found that dentists and the dental hygienists could recognize signs and symptoms of abuse and neglect.

\section{Discussion}

The findings in this study illustrate to what extend the Danish dental staff members fulfill their role in child abuse and neglect matters and thereby contribute to safeguarding children. More than half of the respondents reported to be able to recognize signs and symptoms of abuse and neglect. Over a five-year period, more dental staff members have had a suspicion and reported on their suspicion to the relevant authorities. Despite the activities related to the topic, in terms of information, training, and collaboration with the universities and the dental associations, the barriers to referral remained at an almost similar level over a five-year period in Denmark. A surprisingly high number of the respondents still had not received any training on the topic at all, and close to one third of the respondents found that dentists and dental hygienists could not recognize signs and symptoms of abuse and neglect. Although all members of the dental team could potentially get involved in dental treatment of a child in need of additional social support, this study demonstrates that dentists and dental hygienists treating children had received significantly more undergraduate and postgraduate training than dental staff members not treating children.

The preferred design of the present study would have been to perform a traditional follow-up on the Danish dental population, but due to the formal requirements on anonymity, this was not possible. Therefore, the study design can be considered as a cross-sectional study, but carried out with exactly the same methodology as used by Uldum et al. five years earlier [5]. Recommended 
rules of translating questionnaires have been followed [15]. Today, it is supposedly more common to distribute questionnaires by e-mail or as web-based questionnaires. However, to be able to compare with the study undertaken in 2008 , we decided in the present study to use the same way of distributing questionnaires, i.e., by conventional postal mail.

The response rate has decreased slightly from 2008 to 2013, but was as high as or higher than response rates from similar studies in other countries [6,16-18]. Among colleagues the notion of fatigue of participating in questionnaire studies are discussed. This may explain the slightly lower response rate. However, a response rate close to $70 \%$ is considered reasonable, and the difference in response rate was not statistical significant. Furthermore, the respondents proofed to be representative of the Danish dental staff population. The higher proportion of younger dentists in the sample may have affected the results, but as the sample proofed to be representative of the Danish dental staff population this was not investigated further.

A slight increase in having a suspicion of child abuse or neglect as well as being certain of child abuse and neglect was seen over the five-year period. However, it is notable that suspicions were acted upon more frequently in 2013 compared to 2008 [5]. Still, some suspicions were not acted upon and some concerns were not noted in the clinical record. The fact that not all suspicions were acted upon may be explained by the major barriers, e.g. uncertainty about findings and lack of knowledge of the referral procedures. The notes made in the clinical record without referring to social services may reflect a concern that was raised, but not perceived conclusive enough to act upon, e.g. an unexplained bruise. Making a note in the clinical record may signify an intent to follow up upon the findings at future visits. The findings in the present study on having a suspicion and referring to social services among the Danish dental staff are both consistent with and in contrast to findings from other countries $[6,16,17]$. In Scotland, a similar percentage (37\%) of having a suspicion was found [6], whereas only $11 \%$, in contrast to $50.0 \%$ in Denmark, had made a 
referral to social services. The same pattern was found in Croatia [18] and in New South Wales, Australia [19]. The increase in referrals to social services in Denmark may reflect the encouraging fact that members of the Danish dental team have become more aware of their role in safeguarding children, or the discouraging fact that more Danish children are in need of additional social support. A vast majority of the respondents would choose colleagues and social services as resource persons or agency to communicate with in a hypothetical or an actual case of abuse or neglect, whereas only a third of the respondents would discuss their concern with the caregiver. These findings are consistent with findings from 2008, and results are similar to findings from Scotland [6,7]. It is worth noticing that the majority of the respondents did not involve the caregiver in neither an actual nor a hypothetical case of abuse or neglect, although the caregiver is an essential individual to collaborate with when securing the child additional social support. The exception to involve the caregiver is if the caregiver is suspected of a criminal offense towards the child, i.e., violence or sexual abuse. Thus, it appears that colleagues and social services staff have an important role to play for dentists and dental hygienists in the decision making of whether to refer a child in need of additional support, whereas sharing a concern with the child's caregiver is less common.

The major barriers to referral to social services identified in this study are similar to the barriers identified five years ago in Denmark [5]. The findings are consistent with findings from several other studies $[6,7,18,20,21]$. These barriers may partly explain the relatively high number of nonreferrals. It is reassuring, though, that the barriers can be rectified through continuous focus on undergraduate and postgraduate training and through raising awareness on the importance of intercollegial collaboration.

Significantly more dentists and dental hygienists treating child patients had received undergraduate and postgraduate training on child abuse and neglect issues compared to dentists and dental hygienists not treating child patients on a regular basis. Furthermore, significantly more 
dentists and dental hygienists employed in municipal dental services had received undergraduate and postgraduate training on the topic compared to staff in private practice. The findings on the role of training on the topic are consistent with finding from different countries [6,7,19,20,21]. In Scotland only $29 \%$ had received formal undergraduate training. Despite the fact that child abuse and neglect is not particularly rare in Denmark [23], it is noteworthy to consider that the topic competes with many other disciplines of odontology for the attention of dental staff seeking training and postgraduate education. Child abuse and neglect issues need to be addressed continuously in order to maintain the diligence of the dental staff.

In conclusion, the Danish dental staff members appear to be more and more aware of the importance of their role in identifying and referring children in need of additional support to social services. Despite increased activities, such as information and training on the topic, the barriers to referral have remained unchanged over a five-year period. A surprisingly high number of dental staff members still had not received any training on the topic at all. In Denmark, there is no formal requirement or demand for documentation of the completion of postgraduate courses. The Health Act section 17, however, states that all health professionals must exercise; 'care and conscience in all matters'. There is still a need for further undergraduate and postgraduate training and new approaches to inter-collegial collaboration, and we must continue to strive to close the gap between having suspicion and actually making a referral. 


\section{Acknowledgements}

The Association of Public Health Dentists in Denmark (DOFT) and the Danish Dental Association supported this study. The Association of Public Health Dentists in Denmark, the Danish Dental Association, and the Danish Association of Dental Hygienists provided membership lists.

The authors would like thank professor emeritus Sven Poulsen for constructive criticism of a previous version of the manuscript.

\section{Conflict of interest}

The authors declare no conflict of interest. 


\section{References}

[1] Harris JC, Sidebotham PD, Welbury RR. Safeguarding children in Dental Practice. Dent Update 2007; 34: 508-517.

[2] Welbury RR, MacAskill SG, Murphy JM, Evans DJ, Weightman KE, Jackson MC, Crawford MA. General dental practitioners' perception of their role within Child Protection - A qualitative study. Eur J Paediatr Dent 2003; 2: 1-7.

[3] Kvist T, Annerbäck EM, Sahlqvist L, Flodmark O, Dahllöf G. Association between adolescents' self-perceived oral health experiences of abuse. Eur J Oral SCI 2013; 121: 594599.

[4] van Dam BAF, van der Sanden WJM, Bruers JJM. Recognizing and reporting domestic violence: attitudes, experiences and behavior of Dutch dentists. BMC Oral Health 2015;15:159.

[5] Uldum B, Christensen HN, Welbury R, Poulsen S. Danish dentists' and dental hygienists' knowledge of and experience with suspicion of child abuse and neglect. Int J Paediatr Dent 2010; 20: 361-365.

[6] Harris CM, Welbury R, Cairns AM. The Scottish dental practitioner's role in managing child abuse and neglect. Br Dent J 2013; 214: E24.

[7] Cairns AM, Mok JYQ, Welbury RR. The dental practitioner and child protection in Scotland. Br Dent J 2005; 199: 517-520.

[8] Becker DB, Needleman HL, Kotelchuck M. Child abuse and dentistry: Orofacial trauma and its recognition by dentists. J Am Dent Assoc 1978; 97:24-28.

[9] da Fonseca MA, Feigal RJ, ten Bensel RW. Dental aspects of 1248 cases of child maltreatment on file at a major county hospital. Pediatr Dent 1992; 14: 152-157.

[10] Jessee SA. Physical manifestations of child abuse to the head, face and mouth. J Dent Child $1995 ; 62: 245-249$. 
[11] Jessee SA, Rieger M. A study of age-related variables among physically abused children. ASDC J Dent Child 1996; 63: 275-280.

[12] Welbury RR, Murphy JM. The Dental Practitioners role in protecting children from abuse: 2. The orofacial signs of physical abuse. Br Dent J 1998; 184: 61-65.

[13] Cairns AM, Mok JYQ, Welbury RR. Injuires to the head, face, mouth and neck in physically abused children in a community setting. Int J Paediatr Dent 2005; 15: 310-318.

[14] World Health Organisation Definition of Child Abuse and Neglect www.who.int/topics/child_abuse/en

[15] Behling O, Law K. Translating questionnaires and other research instruments: Problems and Solutions. Edited by: Lewis- Beck MS. Thousand Oaks: Sage; 2000: 1-70.

[16] Owais AIN, Qudeimat MA, Qodceih S. Dentists' involvement in identification and reporting of child physical abuse: Jordan as a case study. Int J Paediatr Dent 2009; 19: 291-296.

[17] Mogaddam M, Kamal I, Merdad L, Alamoudi N. Knowledge, attitudes, and behaviors of dentists regarding child physical abuse in Jeddah, Saudi Arabia. Child Abuse Negl 2016; 54: 43-56.

[18] Cukovic- Bagic I, Dumancic J, Kujundzic T, Drvaric I et al.. Croatian dentists' knowledge, experience, and attitudes in regard to child abuse and neglect. Int J Paediatr Dent 2015; 25: 444-450.

[19] Kilpatrick NM, Scott J, Robinson S. Child protection: a survey of experience and knowledge within the dental profession of New South Wales, Australia. Int J Paediatr Dent 1999; 9: 153159.

[20] Ramos-Gomez F, Rothman D, Blain S. Knowledge and attitudes among California dental care providers regarding child abuse and neglect. J Amer Dent Ass 1998; 129: 340-348. 
[21] Lazenbatt A, Freeman R. Recognizing and reporting child physical abuse: a survey of primary healthcare professionals. J Adv Nurs 2006; 56: 227-236.

[22] Thomas JE, Straffon L, Inglehart MR. Child Abuse and Neglect: Dental and Dental Hygiene Students’ Educational Experiences and Knowledge. J Dent Edu 2006; 70: 558-565.

[23] Christoffersen M, Armour C, Lasgaard M, Andersen TE, Elklt A. The Prevalence of Four Types of Childhood maltreatment in Denmark. Clin Pract Epidemiol Ment Health 2013; 9: $149-156$. 


\section{Table 1.}

Distribution of respondents according to gender, age, dental profession, the type of employment, and frequency of being parents.

\begin{tabular}{|c|c|c|c|}
\hline & & Data collected by & Data from the \\
\hline & & Uldum et al. 2010 & present study \\
\hline & & $n=1145$ & $n=964$ \\
\hline Gender * & Female $(\%)$ & $799(70.6)$ & $723(75.0)$ \\
\hline & Male (\%) & $333(29.4)$ & $241(25.0)$ \\
\hline $\operatorname{Age}^{*}$ & $\leq 30$ years $(\%)$ & $134(11.8)$ & $100(10.4)$ \\
\hline & $31-40$ years $(\%)$ & $244(21.6)$ & $253(26.2)$ \\
\hline & $41-50$ years $(\%)$ & $290(25.6)$ & $225(23.3)$ \\
\hline & $51-60$ years $(\%)$ & $315(27.8)$ & $253(26.2)$ \\
\hline & $>60$ years $(\%)$ & $149(13.2)$ & $133(13.8)$ \\
\hline Dental profession & Dental hygienist (\%) & $235(21.6)$ & $233(24.7)$ \\
\hline$* *$ & Dentist $(\%)$ & $851(78.4)$ & $710(75.3)$ \\
\hline Employment $* * *$ & Municipal dental service (\%) & $318(29.3)$ & $270(28.4)$ \\
\hline & Private practice with children $(\%)$ & $339(31.2)$ & $218(22.9)$ \\
\hline & Private practice without children & $378(34.8)$ & $426(44.8)$ \\
\hline & $(\%)$ & $51(4.7)$ & $36(3.9)$ \\
\hline & Other $(\%)$ & & \\
\hline
\end{tabular}


Being a parent $* * * * \quad$ Yes $(\%)$

$924(82.3)$

$788(81.7)$

No $(\%)$

$199(17.7)$

$176(18.3)$

* Information on the age and/or gender was missing for 13 respondents.

** Information on the profession was missing for 26 respondents.

Five had a degree as a dentist and as a dental hygienist. Their responses were included in 'the dentist group'.

*** Information on the type of employment was missing for 14 respondents.

**** Information on being a parent was missing for 22 respondents. 


\section{Table 2.}

Proportion of respondents reporting suspicion of child abuse and/or neglect within the last six months according to the type of employment.

\section{Employment type}

Municipal dental service

Private practice with child patients

$12.6(29 / 230)$

$43.2(114 / 264)$

Private practice without child patients

$6.2(29 / 466)$

Total
Having suspicion of

child abuse and/or

neglect \% (no. of

respondents/total no. o

respondents)
$22.9(60 / 262)$

$1.9(9 / 466)$

Being certain of child abuse

and/or neglect \% (no. of

respondents/total no. of

respondents)

$5.7(13 / 229)$

$8.6(82 / 957)$ 


\section{Table 3.}

Respondents' choice of resource person or agency to communicate with in a hypothetical child abuse and/or neglect case and in actual cases.

\begin{tabular}{|c|c|c|}
\hline Resource person or agency to & Would discuss with or refer & Prefer to discuss with or \\
\hline communicate with* & to in a hypothetical child & refer to in an actual child \\
\hline & abuse or neglect case & abuse or neglect case \\
\hline & $\%$ (no. of respondents/total & $\%($ no. of \\
\hline & no. of respondents) & respondents/total no. of \\
\hline & $(n=964)$ & respondents) \\
\hline & & $(n=196)$ \\
\hline Social services & $81.9(778 / 949)$ & $89.2(174 / 195)$ \\
\hline Colleague & $87.5(835 / 954)$ & $89.2(176 / 196)$ \\
\hline Caregiver & $26.9(251 / 932)$ & $33.2(63 / 190)$ \\
\hline Police & $13.3(125 / 942)$ & $4.7(9 / 193)$ \\
\hline Others** & $21.1(200 / 947)$ & $29.2(57 / 95)$ \\
\hline
\end{tabular}

* More than one answer was possible.

** 'Others' could be spouse and staff working at schools and day-care centers: nurses, teachers and social workers. 